\title{
The Effect of Using Cooperative Learning Method on Tenth Grade Students' Learning Achievement and Attitude towards Biology
}

\author{
Tshewang Rabgay \\ Teacher, Samtse Higher Secondary School, Samtse District, Bhutan, \\ tshewang48@yahoo.com
}

The study investigated the effect of using cooperative learning method on tenth grade students' learning achievement in biology and their attitude towards the subject in a Higher Secondary School in Bhutan. The study used a mixed method approach. The quantitative component included an experimental design where cooperative learning was the independent variable while students' test scores and attitude towards biology were the dependent variables. The subjects of the experiment comprised 82 tenth grade students. The qualitative component included students' and teachers' opinions on cooperative learning collected through questionnaires and lesson observation forms. Data were analysed by calculating means, standard deviations and paired samples t-test. The test score analysis showed that the experimental group had significantly higher scores than the control group. The students' attitude analysis showed that their attitude towards biology improved as indicated by the increase in the level of interest, understanding, satisfaction and their assessment of biology as a less difficult subject. It was recommended among others that cooperative learning method can be used in teaching and learning of biology in schools.

Keywords: cooperative learning method, biology, learning achievement, education, Bhutan, attitude

\section{INTRODUCTION}

Over the last decade, there has been a growing concern both in the Ministry of Education and among international agencies about the quality of education in Bhutan. A study conducted by the World Bank (2009) demonstrated low learning levels and lack of critical thinking, communication and problem-solving skills among Bhutanese students. Further, the Royal Education Council's (2010) study revealed that students perform below expectations of their grade level on both basic and advanced academic skills and lack basic communication and analytical skills.

One of the major factors attributed to students' low level of learning is teachers' ineffective teaching practices (REC, 2009). Traditional lecture-based method is the 
dominant teaching method used. Classroom instructions are facilitated in conventional ways where teachers take the center stage; play dominant roles, and assume role of knowledge transmitters (REC, 2009). They hardly use innovative teaching techniques and instructional practices are not characterized by constructivist approaches. Classroom interactions are predominantly teacher-initiated with students hardly getting opportunities to talk, share ideas or ask questions (Rabgay, 2014). Such learning environments have lead to poor conceptual understanding and low level of academic achievement (REC, 2011). Moreover, it has not stimulated students' innovations, inquiry and scientific thinking but rather encouraged students to cram facts which are easily forgotten (REC, 2011). Students have become passive learners and do not get opportunities to engage actively in the learning process. Students have been found to be relying on teachers to decide what, when and how to learn (Dorji, 2005).

If the trend of teacher-centered teaching continues, the standard of teaching and learning in Bhutan is bound to remain status quo (REC, 2008; Sherab, 2009). With the current need to improve the quality of education in the country, it has become necessary for efforts to be geared towards shifting the pedagogical trend from teacher-centered teaching to learner-centered teaching. Teachers need to use innovative and interactive teaching techniques to bring an overhaul in the teaching trend.

Over the last decade, CL method has emerged as a leading teaching approach to classroom instruction. It has its roots in the constructivist learning theories and represents a shift in educational paradigm from teacher-centered to learner-centered teaching (Muraya \& Kimamo, 2011). Johnson and Johnson (1994) stated that CL is an alternative to traditional classroom teaching methods. Their studies in diverse school setting and over wide range of content areas have revealed that students learning in cooperative group tasks have higher academic test scores, higher self-esteem, greater number of positive social skills and greater comprehension of the content they study. Over 500 research studies back the conclusion that CL produces gains across all content areas, all grade levels, and among all types of students including special needs, high achieving, gifted, urban, rural, and all ethnic and racial groups (Ho \& Boo, 2007). Owing to its wide range of benefits, CL is popularly used in many countries such as the USA, UK, Singapore, Africa, etc.

Despite its popularity in many parts of the world, CL is hardly used by teachers in Bhutan. Although CL is introduced to teachers during their pre-service training, they hardly use it after they become full-fledged teachers. Many researchers (Humphreys, Johnson \& Johnson, 1982: Slavin, 1995) claim that the benefits of CL are not culture bound. It is, therefore, important for Bhutanese teachers to use CL method as an alternative to lecture method. However, studies need to be carried out to determine the effect of CL method. No prior study has been carried out to determine the effect of CL method in Bhutan. Therefore, the study aimed to investigate the effect of CL in Bhutanese school context. 
The subject and the grade chosen to investigate the effect of CL were grade ten and biology because it is among the subjects that most Bhutanese students scored low (Tenzin, Johnson \& Ramachandran, 2006). The Pupils Performance Report of the last three years $(2016,2015,2014)$ prepared by the Bhutan Council of School Examination and Assessment (BCSEA) showed that students' average scores in grade ten biology has not crossed sixty indicating underperformance in the subject. One of the factors why students perform low in biology is their negative attitude towards the subject which they perceive as difficult and less interesting and having low level of learning satisfaction and conceptual understanding (Tenzin, Johnson \& Ramachandran, 2009). Additionally, the impetus for selecting biology comes from the researcher's previous study (Rabgay, 2014) which showed the need to improve the pattern of teacher-student interaction patterns to enhance grade ten students' learning achievement in biology. Other reasons for choosing biology include the considerable importance that the country places on STEM (Science, Technology, Engineering and Mathematics) subjects. The country aims to enhance students learning achievement in STEM subjects to build a human capital with adequate scientific attitude and skills to facilitate its development process.

In order to address the issue of teacher-centred teaching and the low achievement and negative attitude towards biology, teachers need to be exposed to appropriate teaching and learning approaches that are learner centred rather than teacher-centred. The learner-centred teaching and learning approaches actively engage the learner in the learning process for effective mastery of the subject content matter and promotes a positive attitude towards the subject. To improve academic achievement, the teaching approaches adopted by a teacher should make learning more learner-centred so as to promote imaginative, critical and creative skills in the learners resulting in better achievement of instructional objectives. Therefore, the study specifically aimed to determine the effect of using CL method on grade ten students' learning achievement in biology and their attitude in terms of their level of interest, understanding, satisfaction and difficulty in learning the subject.

\section{Research Questions}

1. What is the effect of CL method on grade ten students' learning achievement in biology?

2. What is the effect of CL method on grade ten students' attitude toward biology as indicated by their level of interest, understanding, satisfaction and difficulty in learning biology?

\section{LITERATURE REVIEW}

This section presents the review of literature which includes the definition of CL, principles of CL, theories underlying CL and the effects of CL.

\section{Cooperative Learning}

Johnson and Johnson (1994) defined CL as an instructional use of small groups so that students work together to maximize their own and each other's learning. CL requires cooperative interaction and negotiation of meaning among heterogeneous members 
engaged in tasks in which each group members have both something to contribute to and learn from other members. Kagan (1989) defined CL as a teaching arrangement that refers to small, heterogeneous groups of students working together to achieve a common goal. A common feature in the above definitions is that students work in small groups to achieve a common goal. However, Johnson and Johnson (1994) stated that CL is more than just small group activities. They explain that simply placing students in groups and telling them to work together does not produce cooperative effect by itself but CL is characterized by five essential components which make CL more effective than group activities. These components known as the five principles of CL include (1) positive interdependence (2) individual accountability (3) face-to-face interaction (4) social skills and (5) group processing.

\section{Principles of Cooperative Learning}

Johnson and Johnson (1994) proposed five essential elements that are necessary to construct positive, effective cooperative group learning situations.

\section{Positive Interdependence}

Johnson and Johnson (1987) stated that the heart of CL is positive interdependence. Students must believe that they are linked with others in a way that one cannot succeed unless the other members of the group succeed. Students work on a common goal and they must work in the spirit of 'sink or swim together'. Positive interdependence may be structured by asking group members to (a) agree on an answer for the group (b) make sure each member can explain the answer (c) fulfil assigned responsibilities (Johnson \& Johnson, 1989).

\section{Face-to-face Promotive Interaction}

This element is necessary because of the existence of the first element, positive interaction. It requires children to discuss, share ideas, views and materials, providing and getting feedbacks, encourage to keep one another highly motivated to complete that task they are assigned (Johnson \& Johnson, 1987). This may involve episodes of peer tutoring, temporary assistance, exchanges of information and material, challenging of each other's reasoning, feedback, and encouragement to keep one another highly motivated (Biehler \& Snowman, 1997).

\section{Individual Accountability}

CL groups make each member a stronger individual in his or her own right (Johnson \& Johnson, 1989). Students learn together so that they can subsequently perform better as individuals. To ensure that each member is strengthened, students are held individually accountable to do their share of the work. The performance of each individual student is assessed and the results given back to the individual and perhaps to the group. The group needs to know who needs more assistance in completing the assignment (Johnson \& Johnson, 1989). Teachers can structure individual accountability by giving an individual exam to each student, randomly calling on individual students to present their group's answer, and giving an individual oral exam while monitoring group work. Individual accountability must be structured by requiring each person to learn and teach 
a small portion of conceptual material to two or three classmates (Biehler \& Snowman, 1997).

\section{Interpersonal and Small Group Skills}

Johnson and Johnson (1989) stated that the success of CL group depends on teamwork skill like leadership, decision-making, trust-building, communication, and conflictmanagement. These skills have to be taught just as purposefully and precisely as academic skills. Many students have never worked cooperatively in learning situations and, therefore, lack the needed skills for doing teamwork effectively. So, teachers must often introduce and emphasize teamwork skills through assigning differentiated roles to each group member.

\section{Group Processing}

Teachers are to ensure that members of each CL group discuss how well they are achieving their goals and maintaining effective working relationships (Johnson \& Johnson, 1989). Groups need to describe what member actions are helpful and unhelpful and make decisions about what to continue or change. Such processing enables learning groups to focus on group maintenance, to facilitate the learning of cooperative skills, to ensure that members receive feedback on their participation, and to remind students to practice cooperative skills consistently. Teachers can structure successful processing by allowing sufficient time for it to take place, maintaining students involved in processing, reminding students to use their teamwork skills during processing, and ensuring that clear expectations as to the purpose of processing have been communicated.

\section{Theoretical Underpinnings}

CL has its roots in the social constructivism by Lev Semyonovich Vygotsky (18961934). Vygotsky viewed learning from a socio-cultural perspective. He considered that the roles of culture and society, language, and interaction are important in understanding how humans learn. He asserted that children learn knowledge available in their culture through social interaction with others, especially parents, teachers and peers. He found that the development of individuals, including their thoughts, languages and reasoning process is a result of social interaction. One of the important theories of Vygotsky is Zone of Proximal Development (ZPD). Vygotsky (1978) described ZPD as the distance between the actual development level as determined by independent problem solving and the level of potential development as determined through problem solving. He proposed that children can solve problems under adult guidance or in collaboration with more capable peers. This implies the idea that tasks, which are too difficult for children to master alone, can be learned with guidance and assistance from adults, more-skilled children, or more knowledgeable others. The ZPD captures children's cognitive skills that are in the process of maturing, and these skills can only be honed with the assistance of more-skilled persons such as peers and parents. Vygotsky explained that the upper limit in the zone of proximal development cannot be attained without social interactive support from peers and teachers. The process of providing support to children by parents, teachers and peers within the ZPD is called scaffolding. In Vygotsky's social constructivism, social interaction is an important way in which children learn knowledge 
available in their culture without needing to reinvent it by them. CL is an interactive teaching technique. Its characteristics such as interdependence, face to face interaction and group success are characteristics congruent to the social constructivism theory.

\section{Effects of Cooperative Learning}

Several studies have examined the effects of CL method on students' learning achievement in biology. These studies have revealed that student taught using CL demonstrate better academic achievement in biology. In an experimental research conducted by Ugwuadu and Abdullahi (2012) in Nigeria using CL method to teach biology revealed significant difference between the mean achievement scores of experimental and control groups in favour of experimental group. A similar study by Muraya and Kimamo (2011) in Kenya, also found that CL approach resulted in significantly higher mean achievement scores in biology compared to regular teaching method.Armstrong, Chang and Brickman (2007) in a study that compared CL approach and traditional lecture method in an undergraduate biology course reported that the experimental group that was instructed through CL approach showed greater improvement in overall test scores than control group that was taught using a traditional lecture approach. He further noted that the experimental group performed significantly better on questions requiring both factual knowledge and comprehension than students in the control group who were instructed through the regular lecture format.

The effect of CL has also been investigated in other subjects. Wachanga and Mwangi (2004) reported that secondary school students who were taught chemistry through the CL approach in Nakuru district, Kenya outperformed those who were taught through the traditional teaching approaches. Similarly, Ho and Boo (2007) reported that CL approach increased academic achievement and motivation to learn physics among secondary school students in Hong Kong as compared to those who were taught through the traditional teaching approaches. However, a study by LaCarrubba (1993) using the STAD model of CL concluded that there was no significant difference in science achievement scores of primary school students taught through the CL method and those taught through direct reading activity which was considered as a traditional teaching method. Similarly, More, Flowers and Abu (1992) compared the effects of STAD CL model with the traditional teaching approach in teaching economics and observed no significant differences in students' test scores between the control and experimental groups.

It is evident from the foregoing that in most cases CL promotes students' academic achievements. Such gains in students' academic achievement have been attributed to several characteristics of CL method. Ugwuadu and Abdullahi (2012) attribute to CL method facilitating better conceptual understand of the subject matter as students share ideas and point of views, give and receive support from each member who helps to dig below the superficial level of understanding of the material they learn. Humphrey, Johnson and Johnson (1982) attribute academic achievement to the support students receive from their group members. They explained that individual students tend to give up when they get stuck, whereas students in CL groups find ways to keep going which leaves more chances to be more successful academically. 
Many studies have also investigated the effect of $\mathrm{Cl}$ method on students' attitude towards various subjects. Juweto (2015), examined the effect of CL method on students' achievement and attitude towards biology in secondary schools in Delta State in the United States of America and concluded that CL method increased students' achievement and promoted positive attitude towards studying biology. Similarly, Humphreys, Johnson, and Johnson (1982) found that students studying physical science in a CL treatment group rated their learning experience more positively than did students in competitive and individualistic treatment groups. In a study involving elementary and secondary students who were taught nutrition, Wodarski, Adelson, Todd, and Wodarski, (1980) found that $95 \%$ of the elementary students enjoyed the CL activities and that they had learned a lot about nutrition. However, some studies found that CL has no effect on students' attitude. For example, Bialangi, Zubaidah, Amin and Gofur (2015) found no difference between the attitudes of students taught by jigsaw and guided inquiry in Natural Science class in senior high school in Palu, Central Sulawesi, Indonesia. Schickler (1998) also found no significant differences in posttest attitudes toward biology knowledge between the EG and CG in an urban community college in Florida, USA.

There is abundance of literature on the effect of CL method on students' learning achievement and attitude. However, literature review has not revealed any studies on the effect of CL approach on students' biology achievement scores and attitude towards the subject in Bhutan. Therefore, this study attempts to fill this knowledge gap and contribute to the body of knowledge on CL approach.

\section{METHOD}

\section{Research Design}

The purpose of the study was to determine the effect of CL method on the mean achievement scores in biology of the tenth grade students and their attitude towards biology in terms of the level of interest, understanding, satisfaction and difficulty. Therefore, the study used a mixed method. The qualitative component included students' and teachers' opinions on CL collected through questionnaires and lesson observation forms built on five-point Likert scale. The quantitative component included an experimental design where cooperative learning was the independent variable while students' test scores and attitude towards biology were the dependent variables. According to Robson (2002), an experimental design is employed where participants are assigned to different conditions; there is manipulation of one or more independent variables by the experimenter; there is measurement of the effects of this manipulation on one or more dependent variables; and there is control of all other variables. This study fitted this description of an experimental design in that the effect of CL approach was compared with the regular teaching method at the end of the two weeks of treatment period to determine whether it had a significant effect on the tenth grade students' mean achievement scores and attitude towards biology.

The subjects of the study comprised 82 tenth grade students of Samtse Higher Secondary School. They were divided into two groups, the experimental group (EG) and 
the control group (CG). To ensure the equality of the two groups in terms of academic competence, students were divided equally based on their previous test scores. Two science teachers, Teacher A and Teacher B, were trained for over one week by the researcher on how to implement different CL structures. Teacher A was employed to teach the EG using CL methods while Teacher B and the researcher served as observers of all the lessons in the EG and CG. The CG was taught by Teacher C using normal lecture method. Although the two groups were taught by different teachers, they were taught the same topic 'Transpiration' using fourteen lessons of 55 minutes each. Before the commencement of teaching in both groups, a pre-test and a pre-survey attitude questionnaire were administered to both groups to obtain pre-test scores and attitude scores.

With respect to the treatment procedure, students in the EG were first trained by Teacher A in the first few classes on CL as they had no prior experience of learning in cooperative groups. Teacher A explained how CL groups works followed by small exercises to help students to get acquainted, adjusted and encourage cooperation with the group members. This activity also helped students to get acquainted with Teacher A and prevent out-of-task behaviour. After orienting the students on CL, they were taught the topic 'Transpiration' using various CL structures. The topic was divided into subtopics and taught using relevant CL structures. The CL structures were chosen based on the nature and content of the topic. Table 1 below showed the list of topics and the CL structures used.

Table 1

Lesson topics and CL structures

\begin{tabular}{ll}
\hline Topic & Cooperative learning structures \\
\hline 1. What is transpiration? & Roundtable method \\
2. Importance of transpiration & Team pair solo \\
3. Experiments on transpiration & Group investigation method \\
4. Internal structure of leaf & Group investigation method \\
5. Measurement of transpiration & Group investigation method \\
6. Kinds of transpiration & Student teams achievement division \\
7. Plant factors affecting transpiration & Student teams achievement division \\
8. External factors affecting transpiration & Team jigsaw \\
9. Adaptation to reduce transpiration & Team Jigsaw \\
10. Significance of transpiration & Student teams achievement division \\
11. Direct loss of water by plants & Team pair solo \\
12. Transpiration the pathway & Team jigsaw \\
13. Transpiration pull and other theories & Student teams achievement division \\
14. How much water does a tree lose in a day? & Team pair solo \\
\hline
\end{tabular}

All the lessons in both groups were observed by Teacher B and the researcher using observation forms wherein they filled their observations on the classroom activities during the lesson. The purpose of the lesson observation form was to study the extent to which the lessons were characterized by cooperative learning environment. The observation form was built based on the five principles of CL using five point Likert scale. At the end, a post-test and post-survey questionnaire were administered to both groups to obtain the post-test scores and post-survey attitude towards biology. 


\section{Research Instruments}

Three research instruments were used to collect data: 1. Achievement test 2. Attitude Questionnaire and 3. Lesson observation form. The achievement test consisted of twenty-five multiple choice questions with a maximum score of 25 based on "Transpiration", a topic that was taught to both groups. The test question was evaluated by three lecturers in biology of Samtse College of Education to ascertain its content validity. They ascertained that the test items were based on the content and specific objectives of "Transpiration" as prescribed in the school biology syllabus of Bhutan. To ascertain reliability of the instrument, the test was pilot-tested in another middle secondary school in the district that was not a part of the study. The reliability coefficient was calculated using Cronbach's alpha. During pre-testing a reliability coefficient of $0.66(\mathrm{~N}=96)$ was attained while at post-testing a reliability coefficient was $0.86(\mathrm{~N}=96)$ was attained. Therefore, the achievement test was a reliable instrument and scores obtained using this instrument could be used to make accurate group inferences.

The students attitude questionnaire was built using a five-point scale i.e. strongly agree, agree, neutral, disagree and strongly disagree. It covered interest, understanding, satisfaction and difficulty as the underlying dimensions to measure students' attitude towards biology. The questionnaire was subjected to assess its validity to four lecturers of Samtse College of Education who had experience in educational research. After making few corrections the panel declared the questionnaire was valid for use in the study. To ascertain its reliability, the survey questionnaire was piloted in a middle secondary school where the achievement test question was piloted. A Cronbach alpha reliability coefficient of $0.85(\mathrm{~N}=96)$ was attained and therefore, the instrument was considered reliable for use in the study.

The observation form was prepared based on the five principles of cooperative learning. The purpose of the lesson observation form was to study the extent to which the lessons were characterized by cooperative learning environment. Five point Likert scale was used to rate the items under each principle. The forms were used to observe the fourteen CL lessons of the experimental group.

\section{Data Analysis Approach}

Data analysis was done in three areas (i) Test score analysis (ii) Students' opinion analysis and (iii) Lesson observation analysis. For test score and students' opinion analysis means and standard deviations were computed. Paired samples t-test was used to determine the difference in test scores and change in opinion. The lesson observation analysis was done in order of the five principles of CL. Means and standard deviations were computed for each principle. Each mean represented a level of opinion on the scale which indicated whether or not the principles were followed during the lessons.

\section{FINDINGS}

The data analysis was done in three parts: 1. Test score analysis 2. Students' attitude analysis and 3. Lesson observation analysis. 


\section{Test Score Analysis}

The results of test score analysis showed that the pre-test means of the CG and EG were not different but on post-test the mean of the EG was significantly higher than that of the CG. The analysis is shown in Table 3.

Table 3

Pre-test and post-test comparison

\begin{tabular}{llllr}
\hline & \multicolumn{2}{c}{ Control group } & Experimental group \\
\hline & Pretest & Posttest & Pretest & Posttest \\
\cline { 2 - 5 } & 9.45 & 12.27 & 9.70 & 17.02 \\
SD & 3.15 & 3.09 & 3.02 & 3.33 \\
Mean difference & $12.27-9.45=\mathbf{2 . 8 2}$ & \multicolumn{2}{c}{$16.01-8.70=\mathbf{7 . 3 1}$} \\
Sig. (t-test) & \multicolumn{2}{c}{0.18} & \multicolumn{2}{c}{0.00} \\
Significance level: $>0.05-$ not significant $<0.05-$ significant
\end{tabular}

Significance level: $>0.05$ - not significant, $<0.05$ - significant

\section{Students' Attitude Analysis}

Students' attitude analysis of the EG presented in Table 4 showed that the pre-survey means of interest, understanding and satisfaction in learning biology increased to high levels in the post survey. The level of difficulty of the subject decreased from high in the pre-survey to low in the post survey. The results indicated that students' level of interest, understanding, satisfaction in learning biology increased and found the subject less difficult.

Table 4

Attitude analysis of the experimental group

\begin{tabular}{llllcl} 
& $\overline{\boldsymbol{x}}$ (Pre) & Level of attitude & $\overline{\boldsymbol{x}}$ (Post) & Level of attitude & Sig. (t-test) \\
\hline Interest & 2.66 & Average & 4.01 & High & 0.00 \\
Understanding & 2.53 & Average & 3.79 & High & 0.00 \\
Satisfaction & 2.91 & Average & 3.89 & High & 0.00 \\
Difficulty & 3.92 & High & 1.86 & Low & 0.00 \\
\hline
\end{tabular}

Scales: (i) Significance level: $>0.05$ - not significant, $<0.05$ - significant

(ii) Level of attitude: 0.00-1.50: Very low 1.51-2.50: Low 2.51-3.50: Average 3.51-4.50: High 4.51-5.0: Very High

Table 5 showed the analysis of the students' attitude in the CG. Although there was an increase in the level of interest, understanding and satisfaction and decrease in the level of difficulty, the differences were not statistically significant. The results indicated that there was not much improvement in the CG students' attitude towards biology in terms of their interest, understanding, satisfaction and difficulty.

Table 5

Attitude analysis of the control group

\begin{tabular}{lccccc} 
& $\overline{\boldsymbol{x}}($ Pre $)$ & Level of attitude & $\overline{\boldsymbol{x}}$ (Post) & Level of attitude & Sig.(t-test) \\
\hline Interest & 2.84 & Average & 3.37 & Average & 0.32 \\
Understanding & 2.81 & Average & 2.84 & Average & 0.19 \\
Satisfaction & 2.93 & Average & 3.11 & Average & 0.51 \\
Difficulty & 3.72 & High & 2.86 & Average & 0.17 \\
\hline
\end{tabular}

Scales: (i) Significance level: $>0.05$ - not significant, $<0.05$ - significant 
(ii) Level of attitude: 0.00-1.50: Very low 1.51-2.50: Low 2.51-3.50: Average 3.51-4.50: High 4.51-5.0: Very High

\section{Lesson Observation Analysis}

Table 6 showed the lesson observers' level of opinion on the classroom activities in the EG class. The results of lesson observation analysis showed that teacher observer strongly agreed that cooperative groups were characterized by positive interdependence, face to face interaction and group processing and agreed that students demonstrated individual accountability; and interpersonal and small group skills during cooperative group activities. It indicated that the lessons in the EG were carried out in CL environments.

Table 6

Means and levels of opinion of teachers' observation

\begin{tabular}{lccl}
\hline \multicolumn{1}{c}{ Principles of CL } & Mean & SD & \multicolumn{1}{c}{ Level of Opinion } \\
\hline Positive Interdependence & 4.67 & 1.2 & Strongly agree \\
Face to face interaction & 3.97 & 2.1 & Agree \\
Individual accountability & 4.72 & 1.7 & Strongly agree \\
Interpersonal and small group skills & 3.9 & 2.4 & Agree \\
Group processing & 4.12 & 2.2 & Agree \\
\hline
\end{tabular}

Level of opinion: 0.00-1.50: Strongly agree 1.51-2.50: Disagree 2.51-3.50: Moderate

$$
\text { 3.51-4.50: Agree 4.51-5.0: Strongly Agree }
$$

\section{DISCUSSION}

The study had two major findings. Firstly, CL method increased tenth grade students' academic scores in biology. Secondly, CL method improved students' attitude towards biology as indicated by their increased level of interest, understanding, satisfaction and their assessment of biology as a less difficult subject. The first finding was consistent with Ugwuadu and Abdullahi's (2012) study who found that students studying biology by CL method learned, retained and scored better than students taught by lecture method. The finding was also congruent with the findings of Kimamo and Muraya (2011) that there were significant gains in the mean test scores in biology of students taught using CL compared to the students in CG taught using lecture method.

Several reasons could be attributed to the gain in student's academic scores. These reasons are mostly characteristic of CL method that promoted effective learning. Firstly, it is attributed to the socially oriented learning environment of CL method that facilitated effective learning (Vygotsky, 1978). Such learning environment in the EG enabled students to interact, share ideas and support each other in their learning (Johnson \& Johnson, 1990). Students' active interaction was evident from the lesson observation analysis in Table 6. The teacher observer's comments also indicated there was active interaction in the class:

"Group members actively engage in the group discussion. Members take turns to share ideas. The group leader writes the ideas shared by the members. Members help by asking probing questions to the friend who has difficulty sharing idea and understanding the concept. The teacher walks around from group to group." (Teacher B) 


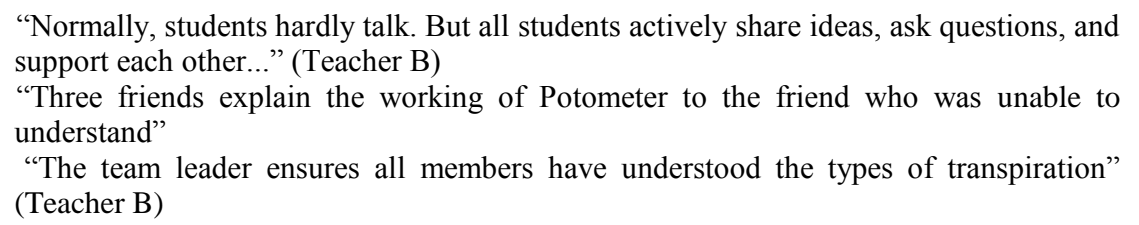

Such interaction among group members could have led to better understanding of concepts and memory retention as Dale (1946) claimed that student retain 50\% of what they learn through discussions and $90 \%$ of what they learn by teaching their peers. Another characteristic of the classroom environment to account for the increased test score is the unintimidating environment where students could freely express their ideas, clarify doubt and seek support from peers. According to Johnson and Johnson (1990), when students interact, share ideas and point of views, give and receive support from group members and help each other, it enables them to dig below the superficial level of understanding of the material they are learning. The prevalence of such learning environment in the EG was evident from the lesson observation analysis as well as the teacher observer's notes:

“...The teacher does not impose any hard rules that would intimidate the students. The teacher is friendly. Students frequently go to the teacher asking help. Students do not hesitate to ask questions to the teacher." (Teacher B)

"Teacher creates an unintimidating classroom environment... There is two-way interaction between the teacher and students" (Teacher B)

The other plausible reason to account for such gains could be the equal opportunity that each member in the group had for success. Students in a group learnt in the spirit of 'Sink or swim together' (Johnson \& Johnson, 1987) and they made sure that each member has understood the material they were learning. This was also evident from the observer notes stating that 'Students made sure that all members in the group had learnt'. It was also evident from the researcher's lesson observation notes that the group leader asked questions to check each member's understanding of the concept they discussed.

The second finding showed that there was improvement in students' attitude towards biology as indicated by the increase in their level of interest, understanding, satisfaction and their assessment of biology as a less difficult subject. This was consistent with the findings of Juweto (2015), who examined the effect of CL method on students' achievement and attitude towards biology in Delta State in the United States of America and concluded that CL method increased students' achievement and promoted positive attitude towards studying biology. The results also supported the study of Humphrey, Johnson, and Johnson (1982) who found that students studying physical science in a CL treatment group rated their learning experience more positively than did students in competitive and individualistic treatment groups. It was also consistent with the study of Tjosvold, Marine, and Johnson (1977) who found that students taught by cooperative strategies believed they had learned more enjoyably than did students taught by competitive strategies. 
A possible reason for such change in attitude could be due to the enjoyable learning environment created by the teacher. According to Slavin (1995), such learning environment helps students in psychological wellbeing and increases the level of interest. Normally in Bhutan, teachers are authoritative figures in the class and students hardly get opportunity to share their ideas (Rabgay, 2014).

Another reason for such positive change in students' attitude could be due to the pleasure and satisfaction students derived from understanding the concepts. It was evident from students' high ratings to statements such as 'I learn biology concepts by understanding not by memorization', 'I am satisfied with what I learn in biology class', 'Each biology class makes me happier'. Students' increased level of interest and satisfaction could also be due to the enjoyable learning atmosphere created by the teacher in the EG. The teacher planned quizzes, tests and games at the end of each group activity to make the lesson interesting. For example, in a lesson using STAD, students first learned kinds of transpiration in group and individual tests were conducted without seeking help from peers. The individual scores were added up and the total score were taken as the group score. The group that secured the highest point was rewarded with pens. Students found this CL activity so interesting that even the next lesson had to be conducted using STAD. It indicated that among the five techniques, students enjoyed STAD method the most.

By and large, the increase in students' test scores and improvement in their attitude towards biology was attributed to the characteristics of CL such as social learning context, non-threatening classroom, equal opportunity for success, children constructing their own knowledge and discussions reinforcing retention in memory. These characteristics were missing in the CG. The lack of such learning environment in the CG was noted by the teacher observer and the researcher:

"The teacher takes most of the class time to talk. Students listens to the teacher's talk. Teacher does not provide opportunity for students to share their views on the topic."

"The teacher tells students to ask questions but students are reluctant."

"Teacher asks questions to students but only few students answer the questions... majority of the students do not engage in the classroom discussion"

"The teacher reads and explains the passage in the textbook while students concentrate on the textbook to keep track of teachers reading and explanation"

"The teacher conducts the experiment on transpiration. She sets up the experiment using a bell jar, a potted plant, a cobalt chloride paper, a scale and paper clips following the instructions in the textbook. All the while students observe the teacher's demonstration."

The lack of such learning environment in the CG could be the reason why there was no significant increase in students' test scores and improvement in their attitude towards biology.

\section{CONCLUSION}

This study found that CL approach promoted higher academic achievement of tenth grade Biology students of Samtse Higher Secondary School in biology as compared to lecture based teaching method. The approach also had positive effect on students' attitude towards biology as indicated by their higher level of interest, satisfaction, 
understanding and their assessment of biology as a less difficult subject. Therefore, the benefit of CL method is not culture bound but it is also effective in raising students' academic score and attitude towards biology in Bhutanese school context.

\section{RECOMMENDATIONS}

1. The findings from this study have proven the effectiveness of CL approach in enhancing higher academic achievement in biology and improving attitude towards the subject. Therefore, biology and science teachers in general are encouraged to use CL approach as an alternative to traditional lecture method. On the other hand, it is recommended that in-service and pre-service teacher education training programmes in Bhutan to provide rigorous training on $\mathrm{CL}$ approach. This will ensure that science teachers are well grounded on effective teaching and learning approaches for higher academic achievement in biology.

2. The findings from this study have demonstrated the effectiveness of CL approach in enhancing higher academic achievement in biology. For the benefit of both science teachers and students and considering that CL approach has many other benefits beyond the academic achievement, it should be promoted as the teaching and learning approach of choice. However, for wider application of this approach, some policy guidelines should be formulated to guide the implementation process. In particular, the teachers would require training and reference materials on how to implement CL approach. Therefore, policy makers in education should formulate policy guidelines on modalities of training teachers through in-service and pre-service teacher training programmes on CL approach. Such policy guidelines geared towards implementation of CL approach should also inform on development of curriculum support materials

3. Although CL approach has been widely studied in the developed countries, there are very few studies in Bhutan on the effectiveness of this approach. In addition, the current study focused on the effectiveness of CL approach on promoting academic achievement in biology. There is need, therefore, to conduct more studies in other subjects and further confirm the effectiveness of this approach in the Bhutanese context. In addition, more studies should be conducted at different education levels to gather more evidence on the effectiveness of the approach.

\section{REFERENCES}

Armstrong, N., Chang, S. M., \& Brickman, M. (2007). Cooperative learning in industrial-sized biology classes. CBE Life Sciences Education, 6, 163-71.

Bialangi, M. S., Zubaidah, S., Amin, M., \& Gofur, A. (2016). Development of students' social attitudes in biology classroom through jigsaw and guided inquiry. International Journal of Academic Research and Development. 1 (10), 01-07.

Biehler, R. F., \& Snowman, J. (1997). Psychology applied to teaching, $8^{\text {th }}$ edition. Boston, MA: Houghton Mifflin.

Bhutan Council for School Examinations and Assessment (BCSEA) (2015). Pupil's performance report. Thimphu: Bhutan.

Bhutan Council for School Examinations and Assessment (BCSEA) (2015). Pupil's performance report. Thimphu: Bhutan. 
Bhutan Council for School Examinations and Assessment (BCSEA) (2016). Pupil's performance report. Thimphu: Bhutan.

Dale, E. (1946). Audio-visual methods in teaching. New York: The Dryden Press.

Dorji, J. (2005). Quality of education in Bhutan: The story of growth and change in the Bhutanese education system. KMT Publishers. Thimphu: Bhutan.

Ho, F. F., \& Boo, H. K. (2007). Cooperative learning; exploring its effectiveness in the physics classroom. Asia-Pacific Forum on Science Learning and Teaching, 8(2), 1-20.

Humphreys, B., Johnson, R. T., \& Johnson, D. W. (1982). Effects of cooperative, competitive, and individualistic learning on students' achievement in science class. Journal of Research in Science Teaching, 351-356.

Johnson, D. W., \& Ahlgren, A. (1976). Relationship between student attitudes about cooperation and competition and attitudes towards schooling. Journal of Educational Psychology, 68(1), 92-102.

Johnson, D. W., \& Johnson, R. T. (1989). Leading the cooperative school. Edina, MN: Interaction Book.

Johnson, D. W., \& Johnson, R. T. (1990). Social skills for successful group work. Educational Leadership, 47(4), 29-33.

Johnson, D. W., \& Johnson, R. T. (1994). Learning together and alone, cooperative, competitive and individualistic learning. Needham Heights, MA: Prentice-Hall.

Johnson, D. W., Johnson, R. T., \& Holubec, E. J. (1987). Structuring cooperative learning: lesson plans for teachers. Edina, MN: Interaction Book.

Juweto, G. A. (2015). Effects of jigsaw cooperative teaching/learning strategy and school location on students' achievement and attitude towards biology in secondary school in Delta State. Delta State University Abraka, Nigeria.

Kagan, S. (1989). Cooperative learning resources for teachers. San Juan Capistrano, CA: Resources for Teacher.

LaCarrubba, A. (1993). A comparative study of the academic achievement of primary students when learning science through the directed reading activity or cooperative learning approach. Unpublished dissertation for Masters of Arts in Education. Kean College of New Jersey.

More, G., Flowers, J., \& Abu, R. B. (1992). The effects of cooperative learning methods on achievement, retention, and attitudes of home economics students in North Carolina. North Carolina State University.

Muraya, D. N., \& Kimamo, G. (2011). Effects of cooperative learning approach on biology mean achievement scores of secondary school students' in Machakos District, Kenya. Educational Research and Reviews, 6(12), 726-745.

Rabgay, T. (2014). Patterns of teacher-student verbal interaction in the tenth grade biology class, Samtse District. RABSEL: the CERD Educational Journal, 15, 1-23.

Robson, C. (2002). Real world research: a resource for social scientists and practitioner researchers. Second Edition. Malden. MA. Blackwell Publishing. 
Royal Education Council \& Educational Initiatives. (2008). Bhutan's annual status of student learning. Thimphu: Bhutan.

Royal Education Council \& iDiscoveri Education. (2009). The quality of school education in Bhutan-Reality and opportunities. Thimphu: Bhutan

Royal Education Council \& Educational Initiatives. (2010). Bhutan's annual status of student learning. Thimphu: Bhutan.

Royal Education Council \& Educational Initiatives. (2011). Bhutan's annual status of student learning. Thimphu: Bhutan.

Schickler, G. C. C. (1998). The effect of cooperative learning on the attitudes toward science and the achievement of students in a non-science majors' general biology laboratory course at an urban community college. Unpublished Dissertation for Doctor of Education. Florida International University. Florida: USA.

Slavin, R. (1983). When does cooperative learning increase achievement? Psychological Bulletin, 94, 429-445.

Slavin, R. (1995). Cooperative learning: theory, research and practice $\left(2^{\text {nd }}\right.$ ed. $)$. Boston: Allyn and Bacon.

Sherab, K. (2009). Bhutanese teachers' pedagogical orientation on the primary grades (PP-VI). A factor on quality of education. Centre for Educational Research \& Development Paro College of Education, Paro: Bhutan.

Tenzin, W., Johnson, D., \& Ramachandran, K. (2006). A needs assessment of science education in

Bhutan. http://portal.unesco.org/geography/en/files/11198/12396892105Final_Report.pdf/Final \%2BReport.pdf.

Tjosvold, D., Marine, P., \& Johnson, D. W. (1977). The effect of cooperation and competition on students' reactions to inquiry and didactic science teaching. Journal of Research in Science Teaching, 11(4), 281-288.

Ugwuadu, O. R., \& Abdullahi, S. (2012). Effect of cooperative learning strategy on biology students' academic achievement in Yola Educational Zone of Adamawa State. Knowledge Review. 24(1).

Vygotsky, L. S. (1978). Mind in society: The development of higher psychological processes. Cambridge, MA: Harvard University Press.

World Bank (2009). Findings from the Bhutan learning quality survey. South Asia human development sector series; no. 21. Washington, DC.

Wachanga, S.W., \& Mwangi, J. G. (2004). Effects of cooperative class experiment teaching method on secondary school students' chemistry achievement in Kenya's Nakuru District. International Educational Journal, 5(1), 26-36.

Wodarski, L. A., Adelson, C. L., Todd, M. T., \& Wodarski, J. S. (1980). Teaching nutrition by teams-games-tournaments. Journal of Nutrition Education, 12, 61-65. 